\title{
Development of Groundwater Recharge Model for the Sumanpa Catchment at Ashanti-Mampong-Ashanti Area in Ghana
}

\author{
Kotei Richard ${ }^{1}$, Agyare Wilson Agyei ${ }^{2}$, Kyei-Baffour Nicholas ${ }^{2}$, Nana Kena Frempong 3 , \\ Atta-Darkwa Thomas ${ }^{4}$ \\ ${ }^{1}$ Department of Agriculture Engineering and Mechanization, College of Agriculture Education, University of Education, Winneba, \\ Mampong-Ashanti, Ghana \\ ${ }^{2}$ Department of Agricultural Engineering, College of Engineering, Kwame Nkrumah University of Science and Technology, Kumasi, Ghana \\ ${ }^{3}$ Department of Mathematics, College of Science, Kwame Nkrumah University of Science and Technology, Kumasi, Ghana \\ ${ }^{4}$ Department of Agricultural Engineering, University of Energy and Natural Resources, Sunyani, Ghana
}

Email address:

richstarnaa@yahoo.co.uk (K. Richard),rkotei@uew.gh.org (K. Richard)

\section{To cite this article:}

Kotei Richard, Agyare Wilson Agyei, Kyei-Baffour Nicholas, Nana Kena Frempong, Atta-Darkwa Thomas. Development of Groundwater Recharge Model for the Sumanpa Catchment at Ashanti-Mampong-Ashanti Area in Ghana. Science Research.

Vol. 3, No. 6, 2015, pp. 289-295. doi: 10.11648/j.sr.20150306.14

\begin{abstract}
The research aimed at developing a groundwater recharge model from available and reliable data of recharge predictor variables from 1985-2009 for the Sumanpa catchment in the forest-savannah transitional zone. Streamflow data for the Sumanpa River was generated from daily stage data using the rating curve model developed by the researchers at the gauge station. The streamflow data generated was partitioned into its various components, including runoff and recharge by means of the PART and RORA computer programmes respectively. The relationship between the catchment's groundwater recharge and its predictor variables were determined by means of a scatter plot, using $\mathrm{R}$ statistical package, and their strengths quantified using the Pearson Correlation Test. The test indicated a strong positive correlation between recharge, rainfall and runoff and a strong negative correlation with actual evapotranspiration. Based on these a lumped conceptual deterministic groundwater recharge model was developed for the Sumanpa catchment using the multiple regression analysis.
\end{abstract}

Keywords: Groundwater Recharge, Actual Evapotranspiration, Correlation, Geomorphological, Conceptual

\section{Introduction}

\subsection{Background}

The Water Footprint, as an indicator of water consumption has become increasingly popular for analyzing environmental issues associated with the use of water resources in the global supply chain of consumer goods (Kuishuang et al., 2011) "[1]". Decreases in rainfall interception, transpiration and surface soil hydraulic conductivities associated with forest disturbance, and conversion to pasture or agricultural lands modifies the terrestrial water cycle and may have significant effects on catchment water yields and streamflow dynamics [2]. The river catchment is of critical importance for the success of development programmes. Aquifers of river catchments are recharged directly by precipitation moving down through the soil and rock layers and into water bearing formations and also by infiltration from surface water sources "[2]". Water sources in the Sumanpa catchment are likely to be affected by trends in climate change, landuse and drought periods. There is a positive correlation between water demand and population growth, peri-urban expansion, economic development, and changes in life-style of the people, as the catchment plays host to one University, two Colleges of Education and three Senior High Schools whose annual enrollment keeps increasing. In order to avoid groundwater depletion, there is the need to predict the behaviour of a catchment system as a function of climate change and variability and landuse scenarios. This requires understanding of the basic processes controlling the behaviour of the catchment system through the development of a suitable hydrological model that will adequately determine the behavour and responses of the catchment to external factors. 
The study area has undergone major anthropogenic changes affecting its land cover and morphometric characteristics for over five decades. These changes which may have correlation with groundwater recharge have, however, not been quantified in a manner to allow a wider and more scientific scale of understanding the causative factors and their effects on baseflow parameters. The stream contributes, perennially, significant amounts of water to the Ghana Water Company Limited's reservoir on the Kyirimfa River. There is a conjecture that the amount of water pumped, annually, from the catchment's aquifers is gradually increasing and may catch up with the annual natural recharge magnitudes. Since agriculture is the main source of livelihood of the people the heavy dependence on groundwater is evident in that groundwater is used for both major and dry season irrigation, small scale industrial and domestic activities. There is not much detailed hydrological study in the Sumanpa catchment to establish trends, variabilities and changes in the stream's flow conditions in recent decades.

The research hypothesis was that there was no correlation between the catchment groundwater recharge and its rainfall, runoff, and actual evapotranspiration. The key research questions were:

- What is the correlation between groundwater recharge and rainfall, run-off and actual evapotranspiration?

- What is the optimum groundwater recharge regression model from available and reliable catchment recharge predictor variables?

The objective of the research was to generate data from recharge variables and determine their relationships, directions and magnitudes and develop the optimum groundwater recharge model for the catchment. Specifically the study generated the stream's daily flow data, determined the stream's baseflow components from appropriate streamflow separation method, determined the magnitude of landuse changes, the correlation between the catchment's groundwater recharge and available groundwater recharge variables and developed the optimum groundwater recharge model using multiple regression analysis.

The developed model will serve as a tool for monitoring and forecasting recharge and discharge conditions of the catchment, ascertaining the potential of its hydrological system for development, policy formulation and future research, designing integrated watershed conservation project to improve underground water recharge and streamflow for the growing population and could be used to assess the economic, social, and environmental effects of alternative developments and management policies within the catchment.

\subsection{Related Works}

Studies according to "[3]" suggest that changes in vegetation coverage and structure due to long-term climate change or short-term extreme events such as drought also influence interception lost and the partitioning of precipitation into evapotranspiration and runoff.
Quantifying infiltration, according to [4], is of great importance in catchment management and it is necessary in monitoring groundwater recharge as groundwater is becoming one of the most important natural resources. There has been an increasing focus on its studies, analyses and exploration for monitoring and sustainable exploitation in catchment management. Dynamic global processes, such as climate change, landuse change, urbanization, population growth and economic development produce evident biophysical effects that can seriously threaten water security "[5]". Long-term planning of water resources should take into account the predicted rise in temperature of between 1 and $3.5^{\circ} \mathrm{C}$ over the forthcoming century which will affect water supplies and demands by making the hydrological cycle more vigorous, increasing precipitation and evapotranspiration and affecting runoff, groundwater recharge regime and rivers/stream baseflow conditions [6]. Models offer a simplified representation of problems that enable information to be processed quickly and efficiently. Sustainable development and protection of groundwater resources include integrated groundwater and surface water assessments to ensure that sustainable exploitation of groundwater resources takes place "[7]".

\section{Materials and Methods}

\subsection{Study Area}

The Mampong Municipality, one of the 27 administrative districts in the Ashanti Region of Ghana, is located on the northern part of the region, and shares boundaries with Atebubu, Sekyere East, Afigya-Sekyere and EjuraSekyeredumasi Districts to the north, east, south, and west, respectively. The Municipality is located within longitudes $0.05^{\circ}$ and $1.30^{\circ}$ West and latitudes $6.55^{\circ}$ and $7.30^{\circ}$ North, covering a total land area of $2346 \mathrm{~km}^{2}$. It has about 220 settlements, with about $70 \%$ being rural [8].

The Sumanpa catchment (Fig. 1) has a population of 44,380 with a growth rate of $4.2 \%$ per annum "[9]". The catchment has a relief of $137 \mathrm{~m}$ and an area of $38 \mathrm{~km}^{2}$ [10] bounded by the Mensah Saahene Junior High School, Kontonkyi Guest House, the Mampong Cemetery, Ammaniampong Senior High School, the College of Agriculture Education -Mampong, Tadeeso, Bimma and Daaho Bosofour from the main Kumasi-Mampong-Ashanti trunk road (Fig. 1). The main occupation of the people is agriculture producing major crops such as cocoa and oil palm, cassava, maize and vegetables. In the dry season farmers predominantly cultivate vegetables along the stream banks [9].

\subsection{Hydrology, Climate and Vegetation}

The catchment's drainage pattern is characterized by a network of channels and 12 streams. The site experiences double maximum rainfall with peak periods in May-June and September-October and dry periods between JulyAugust (minor) and November-February (major). The 
climate is typically tropical, with total annual rainfall between $1270 \mathrm{~mm}$ and $1524 \mathrm{~mm}$. Temperatures are uniformly high throughout the year ranging from $25-32^{\circ} \mathrm{C}$ with a daily mean maximum temperature of $30.5^{\circ} \mathrm{C}$. The potential evapotranspiration (PET) is estimated at 1450 $\mathrm{mm} / \mathrm{y}$ [11]. The average humidity during the wet season is typically high $(86 \%)$ and falls to about $57 \%$ in the dry period. The catchment lies within the wet semi-equatorial forest zone and the forest savanna transitional zone of the Ashanti Region [11]. The vegetation of the eastern part of the catchment's stream is gradually being reduced to savannah grassland while the western part is completely urbanized [10].

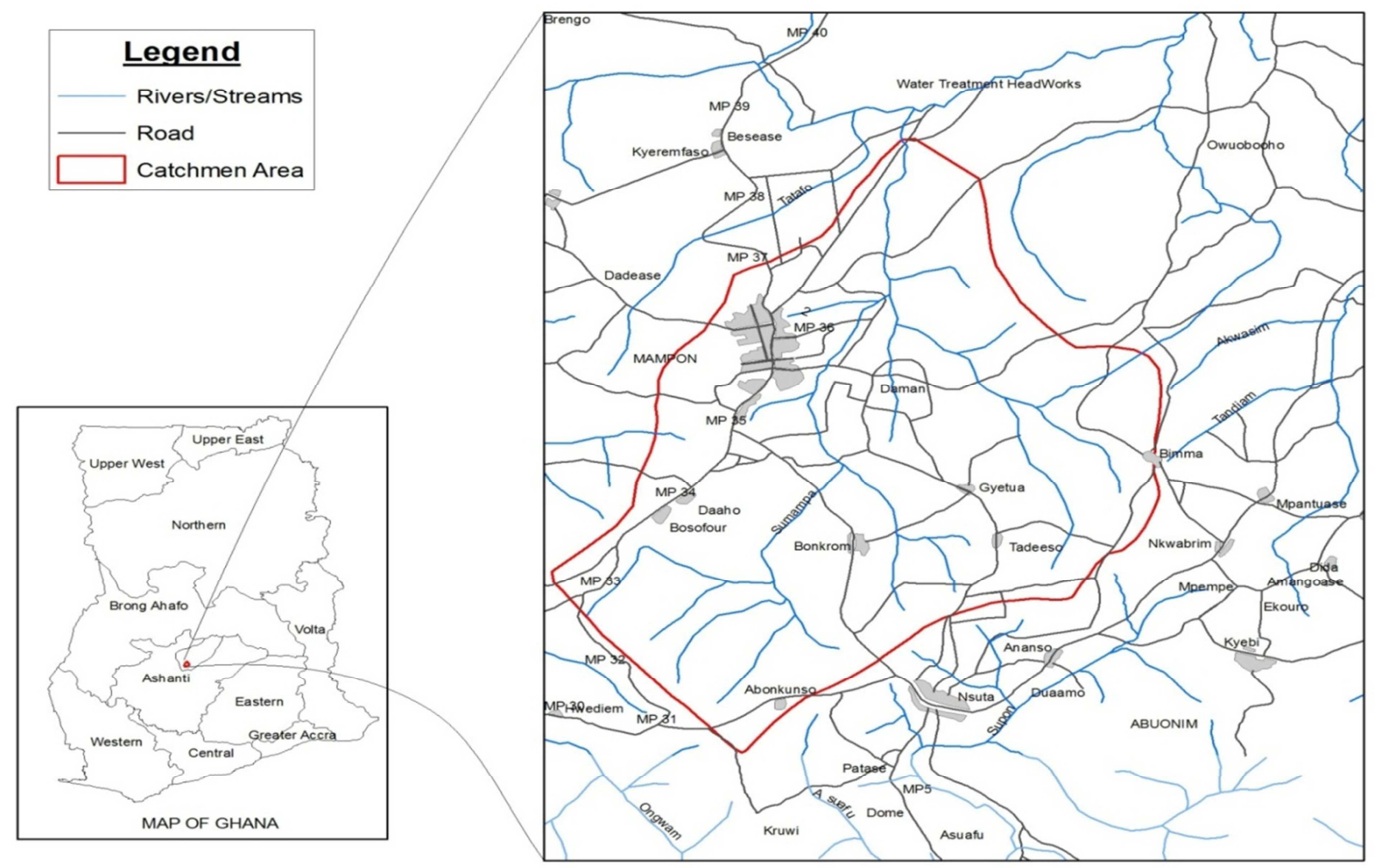

Figure 1. Location of the Catchment Area of the Sumanpa Stream in the Mampong-Ashanti Municipal Area.

\subsection{Geology and Topography}

In considering the groundwater resources of the Sumanpa catchment, the geological formations have to be considered. The main geological formation is the consolidated sedimentary formations underlying the Volta Basin (including the limestone horizon) which characterizes the catchment area's ground structure [12].

\subsection{Catchment Soil}

Very shallow, eroded, exclusively well-drained, rocky lithosols, mainly sandstone outcrops occurr in summits and upper slopes of moderately undulating land (Yaya Series); moderately shallow humus, redish brown, well-drained, loose, ironstones concretions overlying weathering sandstone rock on gentle upper slopes (Pimpimso Series). These soils occur in association with very deep to moderately deep, humus, red, well drained (Bediesi Series) and moderately well-drained, yellowish red (Sutawa Series), fine sandy loams to clay loams found on gentle upper and middle slopes. The lowland soils comprise very deep to deep, brownish yellow imperfectly to poorly drained, loamy and very deep to deep, poorly drained, grey, loose loamy sands found on broad valley bottoms (Bejua Series) "[13]". The soil which normally occurs on the upper middle slopes was from the Voltaian sandstone of the Afram plains. It is classified as Chromic Luvisol by the FAO/UNESCO legend "[13]".

\subsection{Rating Curve Equation and Streamflow Data Processing}

The daily streamflow data was generated by uploading daily stream stage data for the period [14] from the Hydrological Services Agency (HSA), Kumasi, into the rating curve developed at the stream gauge station using the float method. The data of discharge $\left(\mathrm{m}^{3} / \mathrm{s}\right)$ was converted into daily flows for the entire period. The mean streamflow for a month in a particular year was determined from the daily flows for that month, whereas, the long-term mean monthly flow was based on the average for all monthly flows for the period of record. Mean annual flow was obtained by dividing the sum of all the individual daily flows by the number of daily flows recorded for the year. The mean period flow was calculated by dividing the sum of all the individual flows by the number of flows recorded for the period of record. 


\subsection{Hydrograph Separation for Baseflow and Recharge Data}

The RORA and PART computer programmes were used to estimate daily groundwater recharge to the water-table using the recession-curve-displacement method as described by [15] and daily baseflow and runoff records as described by [16] respectively from daily streamflow data generated from the rating curve model. The method has the ability to simulate groundwater contribution to streamflow and vice versa. Regulation and diversion of streamflow were considered negligible [16]. RORA has been used to estimate recharge for a number of studies of local to regional scope in the USA. Comparisons to other recharge methods were conducted by [17] who found that RORA estimates agreed well with other methods but [18] found that RORA results were significantly greater than estimates from the other methods.

\subsection{Developing the Lumped Conceptual Recharge Model Structure}

The first major stage was the development of a model structure of appropriate complexity with respect to performance and associated uncertainty which is a function of:

- Key processes in the catchment' conceptual model,

- Modelling purpose,

- The hydrological characteristics of the catchment drainage system,

- Establishing and quantifying the relationships between recharge and its predictor variables

- Available data on predictor variables and

- The use of multiple regression for the model [19].

According to [19], conceptual models are based on two criteria: firstly, the structure of the model is specified prior to any modelling being undertaken, and secondly not all of the model parameters may have a direct physical interpretation (i.e. they are not independently measurable). Therefore some conceptual model parameters were estimated through calibration against observed data. Conceptual model applied in the study, generally represented all of the components of hydrological processes perceived to be of importance at the catchment scale inputoutput relationships [20].

To accurately model the hydrology of the Sumanpa catchment, a detailed knowledge of the catchment physical characteristics and processes were determined from literature and reconnaissance survey. Gathering all these information was not feasible in the study area due to lack of complete data on landuse, antecedent soil moisture and detailed information about the hydrological processes in the catchment making it necessary to simplify parameters by lumping or spatially averaging. This implies that in the catchment system, the inputs and responses were represented mathematically using only the dimensions of depth and time. This reduces the parameterization task to simply using one value for each parameter for the whole catchment "[21]". The lumped conceptual catchment recharge model, therefore, provided a single recharge estimate for the entire Sumanpa catchment and therefore it may not be well suited to applications with real hydrological systems.

\subsection{Correlation Analysis}

The degree of dependence between the variables was assessed through the correlation analysis. The measure of correlation, which is called the correlation coefficient, summarises in one number the direction and magnitude of correlation.

Let $\left(\mathrm{x}_{\mathrm{i}}, \mathrm{y}_{\mathrm{i}}\right), \mathrm{i}=1,2 \ldots n$ be the $n$ pairs of observations of the random variables $X$ and $Y$. Then the sample correlation coefficient of these two variables is given by:

$$
r=\frac{\frac{1}{n} \sum_{i=1}^{n}\left(X_{i}-\bar{X}\right)\left(Y_{i}-\bar{Y}\right)}{S_{x} S_{y}}
$$

Where:

$\bar{x}$ and $S_{x}$ are mean and standard deviation of the $X$ variable, and $\bar{Y}$ and $S_{y}$ are mean and standard deviation of the $\boldsymbol{Y}$ variable.

When the variables are independent, $r$ approaches zero. When $r$ equals +1 the variables are said to be perfectly positively correlated and when $r$ equals -1 , they are said to be perfectly negatively correlated "[22]".

The extent of correlation between the variables was quantitatively ascertained by preparing the scatter diagram, which is a graphical plot between the observed values of the variables. The correlation coefficient as defined by Equation (1.0) is a measure of linear dependence only. In other words, even when the computed correlation coefficient is very small $(\mathrm{r} \cong 0)$, it is possible that some form of non-linear dependence may still exist between the variables.

The coefficient of determination, $\mathrm{D}$, which is the square of the correlation coefficient $\left(D=r^{2}\right)$, is perhaps more convenient and used in interpretation of the linear dependency between recharge and its predictor variables. Because it is a measure of the variance, explained in one variable by depending on the other variable. That is,

$$
D=\frac{\text { Variance explained }}{\text { Total variance }}
$$

\subsection{Multiple Linear Regression Models}

Multiple regression is one of the most widely used statistical techniques. It includes the basic technique of parameter estimation, confidence interval estimation and model adequacy checking for multiple regression. It also includes model building and variable selection, autocorrelation in the errors, and multicollinearity or nearlinear dependence among the regressors. The method of least squares was used to estimate the regression coefficients after which the statistical properties of the least-squares estimator, $\hat{\boldsymbol{\beta}}$, the confidence interval estimates for the regression coefficients, $\beta_{\mathrm{j}}$, were constructed using $R$ statistical package. 


\subsection{Developing the Lumped Conceptual Deterministic Recharge Model Structure}

In developing the recharge model structure the following steps were followed:

- The key processes in catchment recharge were determined from a scatter plot constructed by importing and formatting the values of recharge and its predictor variables into the $\mathrm{R}$ using excel.

- The strength and direction of the relationships were estimated using the Pearson correlation test statistic in R. The Sumanpa stream catchment recharge model was developed by importing the data of recharge and its predictor variables into $\mathrm{R}$ using excel.

\section{Results and Discussion}

\subsection{Time Series Recharge Regression Model}

Establishing the dependency between the groundwater recharge and its predictor variables is crucial to catchment water resource development, management and policy formulations. Rainfall and runoff are positively correlated with recharge as seen in Figures 2 and 3. The Loess estimator shows an increasing relationship; as the rainfall increases runoff and recharge increase as expected. The curvilinear shape of the $\mathrm{ET}_{\mathrm{a}}$-recharge relationship indicates that higher $\mathrm{ET}_{\mathrm{a}}$ as well as lower $\mathrm{ET}_{\mathrm{a}}$ is associated with a decrease in groundwater recharge. The strength of the relationship is seen in how the points cluster about the mean line. From the loess estimator, there is a strong relationship between recharge and rainfall, runoff and actual $\mathrm{ET}_{\mathrm{a}}$.

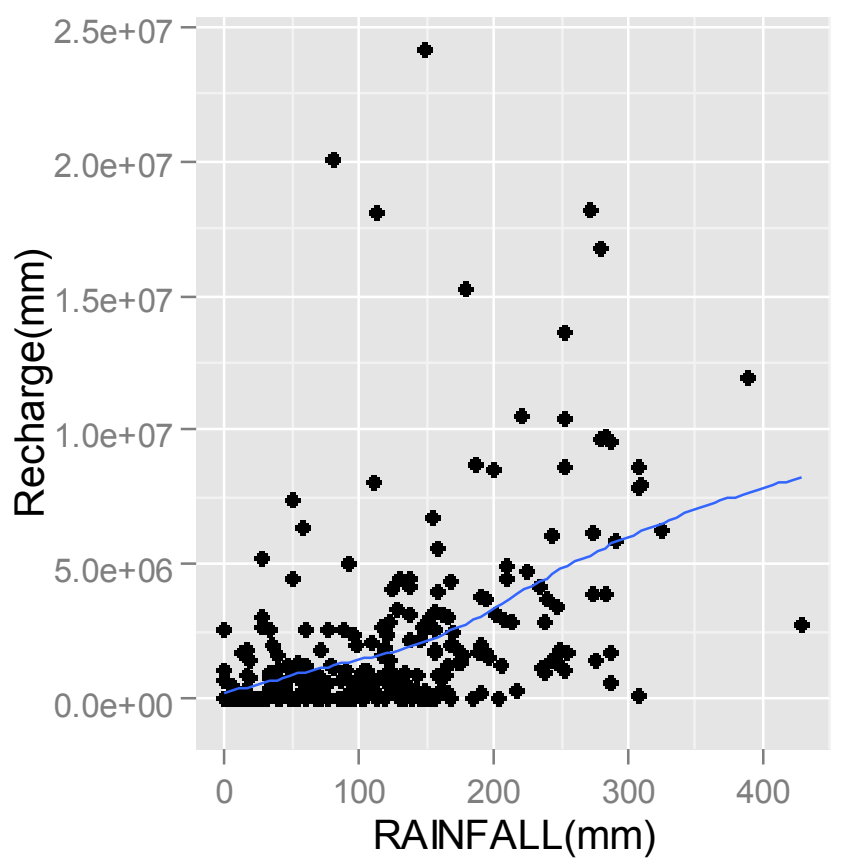

Figure 2. Correlation between recharge and rainfall.

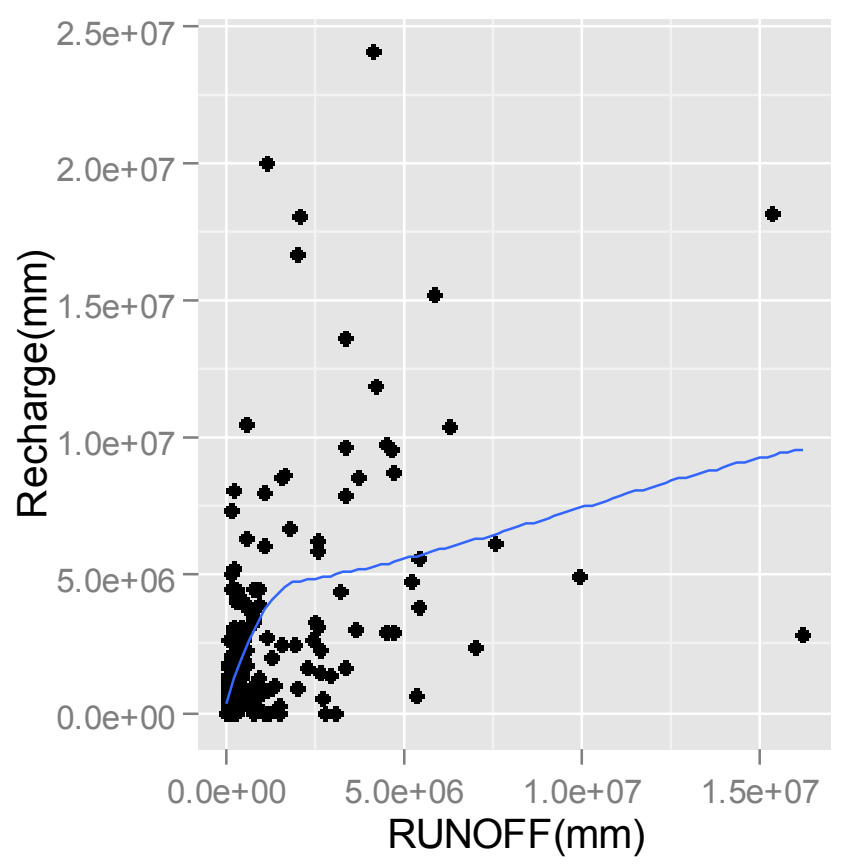

Figure 3. Correlation between groundwater recharge and runoff.

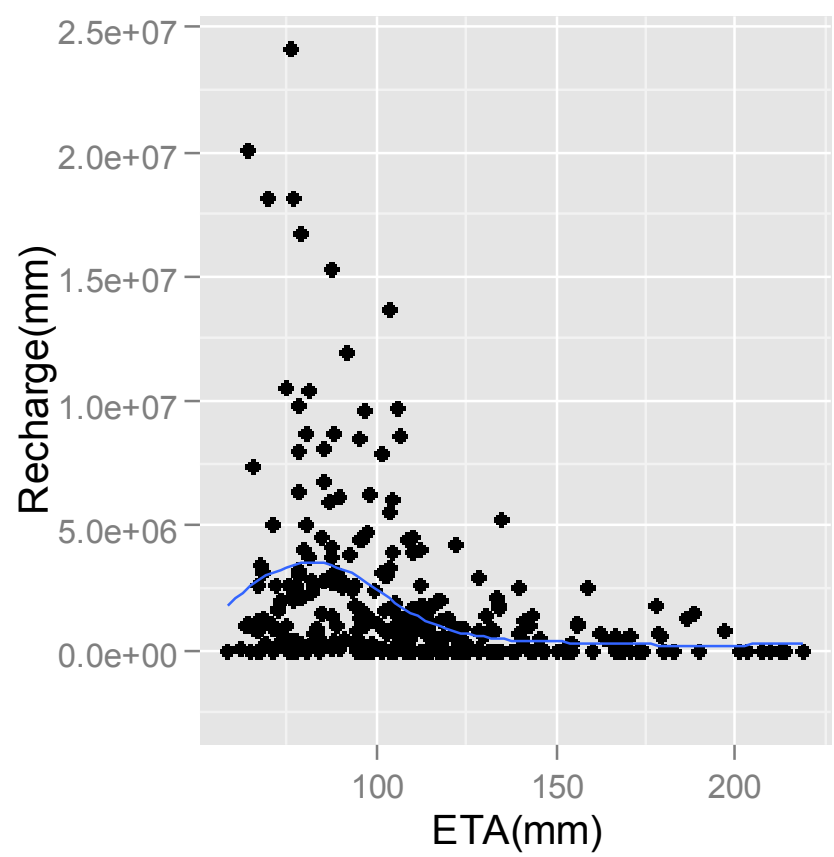

Figure 4. Correlation between groundwater recharge and actual evapotranspiration.

Pearson correlation test statistic was used to determine whether there is a trend and if both variables increase or decrease or one decrease as the other increases, or if their patterns of variation are completely unrelated. The goal of this study was to determine the strength of correlation between groundwater recharge and rainfall, runoff and $\mathrm{ET}_{\mathrm{a}}$ and the results are presented in Table 1. 
Table 1. Quantifying the Relationship between the Recharge and its Predictor Variables.

\begin{tabular}{llllll}
\hline Predictive Variables & Test statistic Value (t) & Degree of freedom & p-value & $\mathbf{9 5 \%}$ confidence interval & Sample correlation estimates \\
\hline Rainfall & 9.261 & 298 & $<2.2 \mathrm{e}^{-16}$ & {$[0.380 ; 0.556]$} & 0.473 \\
Runoff & 14.577 & 298 & $<2.2 \mathrm{e}^{-16}$ & {$[0.574 ; 0.707]$} & 0.645 \\
ETa & -5.630 & 298 & $4.172 \mathrm{e}^{-8}$ & {$[-0.409 ;-0.204]$} & -0.310 \\
\hline
\end{tabular}

The Pearson correlation test was used to quantify the relationship between recharge and its predictor variables. There is a strong positive relationship between recharge and rainfall $(t=9.26)$, a strong positive relationship between recharge and runoff $(\mathrm{t}=14.58)$ and a strong negative relationship between recharge and actual evapotranspiration $(t=-5.63)$ (Table 1). The sample correlation estimates for all the three relationships fall within their respective $95 \%$ confidence intervals (Table 1). All the reported p-values indicate evidences against the null hypothesis that the association is horizontal. That is, a unit increase in rainfall causes a unit increase in recharge. It means that, a significant proportion of the recharge values can be accounted for by the rainfall, runoff and actual evapotranspiration. This means high runoff and high $\mathrm{ET}_{\mathrm{a}}$ will deny the aquifer of maximum recharge but low runoff will increase recharge since the contact time for the waterinfiltration surface is increased and low $\mathrm{ET}_{\mathrm{a}}$ will increase groundwater recharge.

\subsection{Catchment's Lumped Conceptual Deterministic Recharge Model Structure}

From Tables 2 and 3, the model coefficients estimated from the HSA's rating curve model are very small compared to those from the model developed by the authors in 2009 at the gauge station. The models are, however, the same in structure. The model coefficients are far lower for the Agency's model and therefore gave very low predictions. The first column in Tables 2 and 3 gives estimates of each $\beta$ coefficient and the second column gives the "standard error" (i.e., the standard deviation which would be obtained from repeatedly estimating the $\beta$ coefficients on similar data sets).

The standard errors give a measure of the uncertainty in the estimated $\beta$ coefficient. For forecasting purposes, the " $t$ value" and the "p-value" are of limited interest. The " $t$ value" is the ratio of a $\beta$ coefficient to its standard error and the "p-value" is the probability of the estimated $\beta$ coefficient being as large as it is if there was no real relationship between recharge and its predictor variables. This is useful when studying the effect of each predictor, but is not particularly useful when forecasting. From the coefficients table, there is a significant effect of time, rainfall, runoff and $\mathrm{ET}_{\mathrm{a}}$ on the Sumanpa's catchment groundwater recharge.

Table 2. Model Coefficients Generated by the Rating Curve Developed at the Gauge Station by the authors.

\begin{tabular}{lllll}
\hline Element & Estimate & Std. Error & t value & $\operatorname{Pr}(>|\mathbf{t}|)$ \\
Intercept & -3651 & 895.2 & -4.078 & $5.84 \mathrm{e}^{-5}$ \\
Trend & 1.855 & 0.4489 & 4.131 & $4.70 \mathrm{e}^{-5}$ \\
Rainfall & 0.036 & 0.0513 & 0.705 & 0.48140 \\
Runoff & 0.340 & 0.0332 & 10.233 & $2 \mathrm{e}^{-16}$ \\
$\mathrm{ET}_{\mathrm{a}}$ & -0.293 & 0.1057 & -2.772 & 0.00592 \\
\hline
\end{tabular}

Table 3. Model Coefficients Generated by the Rating Curve Developed from the Hydrological Service Agency's (HSA) Data, Kumasi.

\begin{tabular}{lllll}
\hline Element & Estimate & Std. Error & t value & $\operatorname{Pr}(>|\mathbf{t}|)$ \\
Intercept & $2.706 \mathrm{e}^{-8}$ & $2.231 \mathrm{e}^{-09}$ & $1.213 \mathrm{e}^{+1}$ & $<2 \mathrm{e}^{-16}$ \\
trend & $-1.354 \mathrm{e}^{-11}$ & $1.133 \mathrm{e}^{-12}$ & $-1.195 \mathrm{e}^{+1}$ & $<2 \mathrm{e}^{-16}$ \\
Rainfall & $-4.154 \mathrm{e}^{-12}$ & $1.185 \mathrm{e}^{-13}$ & $-3.505 \mathrm{e}^{+1}$ & $<2 \mathrm{e}^{-16}$ \\
Runoff & 1.000 & $3.046 \mathrm{e}^{-18}$ & $3.283 \mathrm{e}^{+17}$ & $<2 \mathrm{e}^{-16}$ \\
ET $_{\mathrm{a}}$ & $2.984 \mathrm{e}^{-13}$ & $5.602 \mathrm{e}^{-13}$ & $5.330 \mathrm{e}^{-1}$ & 0.595 \\
\hline
\end{tabular}

Residual standard error indicates the degree to which the sample statistic can replace the population parameter. The smaller the value the closer the sample statistic is to the population parameter. The adjusted R-square is a statistic that indicates the percentage of variation in rainfall, runoff and actual evapotranspiration that can be explained by the catchment's groundwater recharge model. From the residual standard error of 55.7 and an adjusted r-squared of $46 \%$ (Table 4) the researchers' recharge model in Equation 3 is therefore proposed for the Sumanpa stream catchment.

Table 4. Statistics of the Recharge Models Developed.

\begin{tabular}{|c|c|c|c|c|c|c|}
\hline Recharge Model & Residual standard error & Degree of freedom & Multiple R-squared & Adjusted R-squared & F-statistic & P-value \\
\hline Researchers' & 55.71 & 295 & 0.4625 & 0.4552 & 63.46 & $<2.2 \mathrm{e}^{-16}$ \\
\hline HSD & 2698000 & 295 & 0.3749 & 0.3664 & 44.04 & $<2.2 \mathrm{e}^{-16}$ \\
\hline
\end{tabular}

The Sumanpa Groundwater Recharge Model is therefore given as:

$$
\hat{Q}_{R c h_{t}}=-3651+1.855 t+0.036 P_{t}+0.339 Q_{R U N_{t}}-0.293 E T a_{t}
$$

Where:

$R c h$ denotes groundwater recharge, $P$ is rainfall, $R U N$ is runoff $^{t}$ and ETa is actual evapotranspiration.

\section{Conclusion}

The stream's daily flow generated from its stage data, and rating curve model developed at its gauge station was separated into its components and used with available climate data to develop the catchment's groundwater recharge model using the scatter plot and multiple regression model. The hydrological model developed will help to ascertain the 
potential of Sumanpa's catchment hydrological characteristics to set the agenda for the successful implementation of the GNWP enacted in 2005 and the development and management of small scale irrigation schemes in the catchment. Ideas about extreme flow levels, and flow pattern will be available to users of water and engineers engaged in designing and planning conservationoriented water systems use. It will also pave way for the sustainable development and organization of the catchment's water resources. Trends, variabilities and changes in climatic factors can be established which will aid the development of a sound environmental protection system. The model developed will serve as a tool for monitoring recharge and discharge conditions under varying catchment characteristics and forecasting the conditions of water supply systems within the catchment. It could also be used to design an integrated watershed conservation project to improve underground water and stream flow. Other model types must be explored in future research for the catchment.

\section{References}

[1] Kuishuang, F., Klaus, H., Jan, M., Yim, L. S., Ashok, C., Yang, Y., Dabo, G. and John, B. (2011). Spatially Explicit Analysis of Water Footprints in the UK, Retrieved 15 October 2015, Available from internet $<$ http://waterfootprint.org/media/downloads/Feng-et-al2011.pdf>.

[2] Roa-Garcia, M. C., Brown, S., Schreier, H., and Lavkulich, L. M. (2011). The role of land use and soils in regulating water flow in small headwater catchments of the Andes, Water Resour. Res., 47: 1-7.

[3] Anderegg, W.R.I., Kane, J.M. and Anderegg, L.D.L. (2013). Consequences of Widespread-tree Mortality Triggered by drought and Temperature Stress. Nature Climate Change, 3: 30-36.

[4] Albhaisi, M., Brendonck, L. and Batelaan, O. (2013). Predicted impacts of land use change on groundwater recharge of the upper Berg catchment, South Africa, Water SA, 39(2):1.

[5] Global Water Partnership (GWP). (2009). A handbook for integrated water resources management in basins. Elanders: Global Water Partnership (GWP) and the International Network of Basin Organizations (INBO).

[6] GWP, (2013). The role of decision support systems and models in integrated river basin management, technical Focus Paper, Global Water Partnership, Retrieved 14 October 2015, Available from internet $<$ http://www.unepdhi.org/ /media/667FEFE1506B4AFC9680 59929B2D4D6F.ashx>.

[7] Ministry of Local Government and Rural development (MLGRD). (2006). Mampong Municipal Assembly, Annual Report, Ministry of Local Government and Rural Development, Ghana. Cited 21 March 2009 Available from Internet

$<\mathrm{http} / / /$ www.ghanadistricts.com/districts/?news\&r=2\&_=26>.
[8] SWDA. (2010). Annual Report, Mampong-Ashant. SekereWest District Assembly.

[9] SWDA. (2008). Annual Report, Mampong-Ashant. SekereWest District Assembly.

[10] Kotei, R., Ofori, E., Kyei-Baffour, N and Agyare, W. A. (2013). Landuse Changes and Their Impacts on the Hydrology of the Sumampa Catchment in Mampong-Ashanti, Ghana. International Journal of Engineering Research \& Technology (IJERT), 2 (8): 2533-2547.

[11] Meteorological Service Agency (MSA). (2006). Annual Report, MSA, Accra.

[12] WARM. (1998). Ghana's Water Resources, Management Challenges and Opportunities. Water Resources Management Study, Government of Ghana, Accra.

[13] Asiamah, R.D., Adjei-Gyapong, T., Yeboah, E., Fening, J.O., Ampontuah, E.O. and Gaisie, E. (2000). Soil characterization and evaluation of four primary cassava multiplication sites (Mampong, Wenchi, Asuansi and Kpeve) in Ghana. SRI Technical Report No. 200, Kumasi.

[14] USGS. (2011). How Streamflow is Measured, Water Science For Schools, USGS, Cited 2 November 2011, Available from Internet $<\mathrm{ttp}: / /$ ga.water.usgs.gov/edu/measureflow.html $>$

[15] Rorabaugh, M.I. (1964). Estimating changes in bank storage and ground-water contribution to streamflow. Publication 63. International Association of Scientific Hydrology, 432-441

[16] Rutledge, A.T. (2000). Considerations for use of the RORA program to estimate groundwater recharge from streamflow records. USGS open-file report 00-156, 44 p.

[17] Delin, G.N., Healy, R.W., Lorenz, D.W. and Nimmo, J. R. (2007). Comparison of local- and regional-scale estimates of ground-water recharge in Minnesota, USA. Journal of Hydrology, 334(12):231-249.

[18] Risser, D.W., Conger, R.W., Ulrich, J.E. and Asmussen, M.P. (2005). Estimates of groundwater recharge based on streamflow-hydrograph methods: Pennsylvania. USGS, OpenFile Report, Reston, Virginia, 2005-1333.

[19] Wheater, H. S., Jakeman, A. J., Beven, K. J., Beck, M. B. and McAleer, M. J. (1993). Progress and Directions in RainfallRunoff Modelling, Modelling Change in Environmental Systems, New York, 101-132.

[20] Wheater, H. S. (2002). Progress in and prospects for fluvial flood modelling. Philosophical Transactions of the Royal Society of London, Series A-Mathematical Physical and Engineering Sciences, 360 (1796).

[21] Burke, W.W. (1995). Diagnostic models for organization development, in Howard, A. and Associates (Eds). Diagnosis for Organizational Change, Guilford Press, New York, 53-84.

[22] Reddy, P. and Jaya, R. (2007). A Textbook of Hydrology. $2^{\text {nd }}$ Ed., Laximi Publications (P) Ltd, 113, Golden House, Daryaganj, New Delhi, 116-124. 